Egyptian Journal of Aquatic Biology \& Fisheries

Zoology Department, Faculty of Science,

Ain Shams University, Cairo, Egypt.

ISSN $1110-6131$

Vol. 24(7): 203 - 210 (2020)

www.ejabf.journals.ekb.eg

\title{
Aquatic microalgae "Anabaena oryzae": phenolic compounds, antioxidant activity and antibacterial activity against Streptococcus mutans oral bacteria
}

\author{
Sayed Rashad ${ }^{1 *}$; Marwa A. Elchaghaby ${ }^{2}$ and Ghadir A. El-Chaghaby ${ }^{1}$ \\ ${ }^{1}$ Regional Center for Food and Feed, Agricultural Research Center, Giza, Egypt \\ ${ }^{2}$ Pediatric Dentistry and Dental Public Health Department, Faculty of Dentistry, Cairo University, \\ Egypt
}

"Corresponding Author: Sayed_rashad79@hotmail.com

\section{ARTICLE INFO}

Article History:

Received: Sept. 13, 2020

Accepted: Oct. 16, 2020

Online: Oct. 19, 2020

\section{Keywords:}

Anabaena oryzae; phenolic compounds; antioxidant activity; antibacterial activity; Streptococcus mutans oral bacteria

\begin{abstract}
Natural antioxidant replacements have been a common subject in recent decades for the substitution of artificial antioxidants. Microalgae have been reported to exhibit interesting bioactive properties especially their antioxidant capacity and antibacterial activity. The goal of the present work is to investigate the possibility of using the blue-green microalgae 'Anabeanae orayzae' for extract preparation and to determine the phenolic compounds that make up this extract and its possible antioxidant and antibacterial capacities by emphasizing the role of the extract in oral disease prevention. The results showed that Anabaena extract possesses a notable antioxidant capacity and also good phenolic compounds content. Algae and cyanobacteria have been demonstrated to produce secondary metabolites with diverse bioactivities. The DPPH scavenging activity of different concentrations of Anabaena extract. As for the DPPH scavenging activity of different concentrations of Anabaena extract, the results show that a concentration of Anabaena extract equal to $2.98 \mathrm{mg} / \mathrm{ml}$ was capable of inhibiting $50 \%$ of the free radicals $\left(\mathrm{IC}_{50}\right)$. Anabaena extract can be thus considered as an excellent antioxidant since its $\mathrm{IC}_{50}$ is a small concentration value and it is agreed that a low $\mathrm{IC}_{50}$ value represents high antioxidant activity. Concerning the phenolic compounds detected in Anabaena extract, they were salicylic acid, gallic acid, tannic acid, caffeic acid, and benzoic acid. The highest concentrations determined in Anabaena extract were for salicylic and tannic acids. In regard to Anabaena extract antibacterial activity against $S$. mutans, the ability of Anabaena extract to inhibit $S$. mutans was tested and the results showed that the extract has an inhibitory effect against $S$. mutans with an inhibition zone diameter equal to $13(\mathrm{~mm})$. It can be concluded that Anabaena extract possesses the potential antibacterial substances that can be used against oral pathogens and for dental caries prevention.
\end{abstract}

\section{INTRODUCTION}

Currently, algae products are extensively explored for their numerous health benefits. Algae are photosynthetic organisms which live in all Earth's aquatic ecosystems. Blue-green algae also known as cyanobacteria are prokaryotic. Secondary cyanobacterial 
metabolites have essential properties (Rashad et al., 2018; Yücer et al., 2018; Rashad and El-Chaghaby, 2020). These aquatic microorganisms represent a vast source of metabolites such as alkaloids, carbohydrates, flavanoids, pigments, phenols, saponins, steroids, tannins, terpenes and vitamins (Rashad et al., 2019). Cyanobacteria are believed to be a rich source of polyphenolics (Singh $\boldsymbol{e t}$ al., 2017), antioxidants and antimicrobials (Seddek et al., 2019).

The phenolic compounds found in algae are interrelated with their antioxidant activity (Seddek $\boldsymbol{e t}$ al., 2019). Phenolic compounds include many classes of substances and can be divided into simple phenols and polyphenols. Phenolic compounds include coumarins, phenolic acids including hydroxybenzoic acids and hydroxycinnamic acids, tannins, esters of gallic acids, flavonoids of which the most important are flavones, isoflavones, flavonols, flavanols, flavanones, chalcones and anthocyanins (Bogdan et al., 2020).

Natural sources of antioxidants and antimicrobials are of high use preference especially in food and in medicine. The role of antioxidants and antimicrobials in delaying food spoilage and also their role in avoiding some dental diseases is quite important. Many oral problems are associated with the presence of reactive oxygen species (ROS). Periodontal disease and dental caries are widely spread chronic conditions affecting people worldwide (Mufeed et al., 2014; Sarangarajan et al., 2017). ROS are implicated in the pathogenesis of periodontal disease as they are released by leukocytes in response to the chronic inflammation which causes oxidative damage to the gingival and the periodontal tissues and the alveolar bone (Sarangarajan et al., 2017). Also, the imbalances in levels of free radicals, reactive oxygen species, and antioxidants in saliva play an important role in the onset and development of dental caries (Mufeed $\boldsymbol{e t}$ al., 2014). At the same time, it is known that oral cavity contains great diversity of microorganisms and despite the fact that these microorganisms are normally considered non-pathogenic but at certain conditions they may lead to diseases, such as dental caries and periodontal diseases (Araújo et al., 2019). In such case it is highly important to use an antibacterial agent to avoid such dental problems.

In this context, the aim of the present work is to investigate the possibility of using the blue-green microalgae "Anabeanae orayzae" for the preparation of extract and to determine the phenolic compounds composing this extract and its potential antioxidant and antibacterial capacities with emphasizing the role of the extract in the prevention of oral diseases.

\section{MATERIALS AND METHODS}

\section{Extract preparation}

The microalgae "Anabaena oryzae" used in the present study was produced under controlled cultivation conditions in the Agricultural Research Center, in Egypt. For extract preparation: $50 \mathrm{~g}$ of dried microalgae were extracted in $200 \mathrm{ml}$ of absolute ethanol 
(HPLC grade). The extraction was done for $1 \mathrm{hr}$ using an ultrasonic bath at room temperature. The obtained extract was concentrated using a rotary evaporator set at $40^{\circ} \mathrm{C}$ (El-Chaghaby et al., 2019).

\section{Analysis of Phenolic compounds}

The phenolic compounds contained in Anabaena extract were determined by HPLC Agilent 1260 infinity equipped with C18 column and diode array detector. Standards of quercetin, pyrogallol, cinnamic acid, salysilic acid, gallic acid, benzoic acid, caffeic acid and tannic acid were obtained from Sigma-Aldrich. The determination of phenolic compounds was done following the procedure given by (Athmouni et al., 2015)

\section{Determination of antioxidant capacity, total phenols and total flavonoids}

The total antioxidant capacity of the extract was determined by the "phosphomolybdenum method" using ascorbic acid as standard (Prieto et al., 1999). The total phenols content of the extract was determined using the Folin-Ciocaleau method using gallic acid as standard (Turkmen et al., 2006). The total flavonoids content of the extracts was determined by the "aluminium chloride" test (Mohdaly et al., 2010) using quercetin as standard.

\section{Determination of free radical scavenging activity}

The free radical scavenging activity of the extract on the stable radical 1, 1diphenyl-2- picrylhydrazyl (DPPH) was also evaluated as earlier reported by Aliyu et al., (2013). Different extract concentrations were tested and the $\mathrm{IC}_{50}$ defined as the amount of antioxidant material required to scavenge $50 \%$ of free radical in the assay was calculated as $\mathrm{mg} / \mathrm{ml}$.

\section{Determination of antibacterial activity}

The antibacterial activity of Anabeana extract was tested against oral bacterial strain: Streptococcus mutans by using the disc diffusion method (Zhou et al., 2018).

All analysis of sample were determined with three replicates and the mean data \pm standard deviation were computed using the Microsoft excel program for windows.

\section{RESULTS AND DISCUSSION}

Antioxidants change the progress of oral problems by compromising antioxidant capacity of crevicular fluid and plasma (Aksakalli, 2013). In the present work, the antioxidant capacity and total phenolic compounds content of Anabaena extract are given in table (1). The results showed that Anabaena extract possess notable antioxidant capacity and also good phenolic compounds content. Algae and cyanobacteria have been demonstrated to produce secondary metabolites with diverse bioactivities (Seddek $\boldsymbol{e t}$ al., 2019). The antioxidant capacity of the extract could be mainly attributed to its phenolic compounds that are secondary metabolites described as radical scavengers because they are donors of hydrogen atoms or electrons, producing stable radical intermediates (JerezMartel et al., 2017). According to Abd El-Aty et al., ( 2014) algae usually have high 
antioxidant activity owing to their high contents of non-enzymatic antioxidant components, including ascorbic acid, reduced glutathione, phenols, and flavonoids.

Table (1): Antioxidant properties of Anabaena extract

\begin{tabular}{l|l|l}
\hline & TAA ppm AAE & TP ppm GAE \\
\hline Mean \pm S.D. & $563.8 \pm 19.07$ & $349.4 \pm 42.59$
\end{tabular}

TAA: total antioxidant and TP: total phenolic

The antioxidant activity is a complex process, usually happening via several mechanisms. Thus evaluation of plant extracts antioxidant activity is better to be tested using more than one test (Lefahal et al., 2018). In this respect, the free radical DPPH scavenging assay was also employed to assess the antioxidant activity of Anabaena extract and the results are depicted in Figure1.

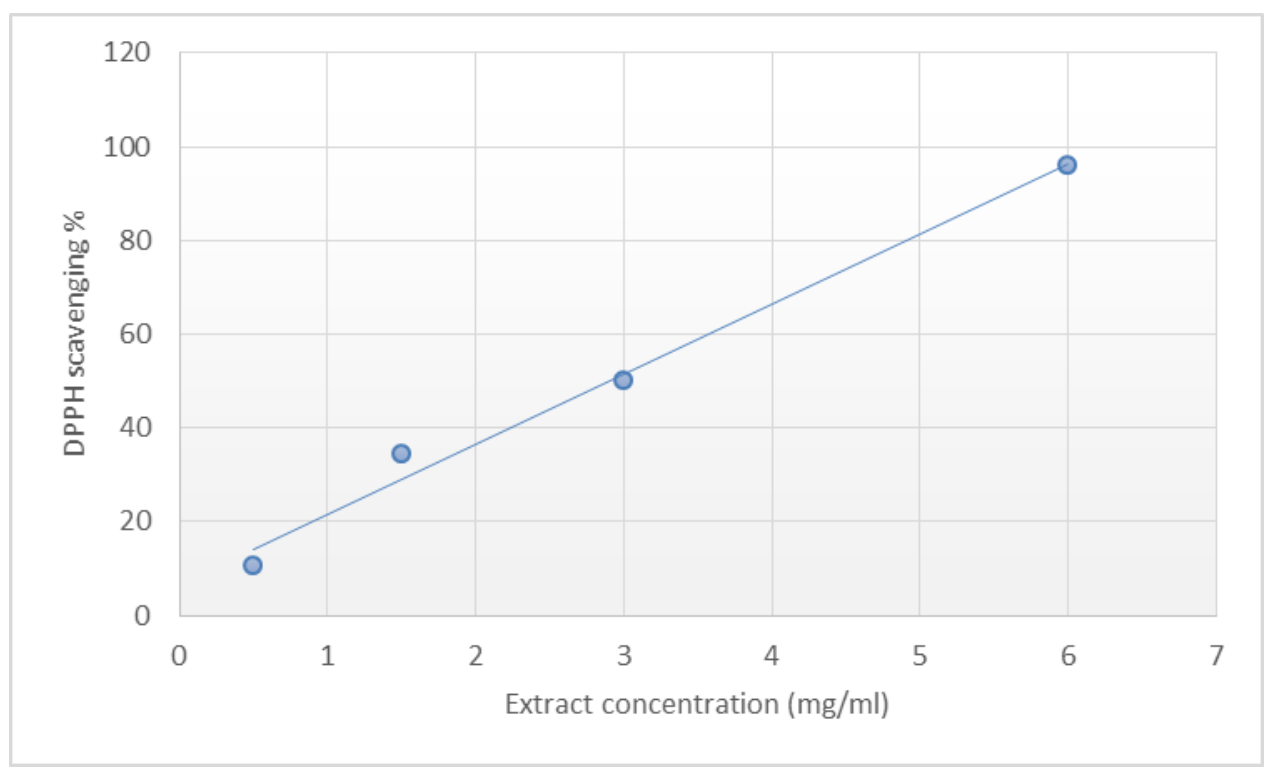

Figure1: DPPH scavenging activity of Anabaena extract

Figure 1 shows the DPPH scavenging activity of different concentrations of Anabaena extract. It is obvious that by increasing the extract concentration its ability to scavenge DPPH free radicals increased. Results show that a concentration of Anabaena extract equal to $2.98 \mathrm{mg} / \mathrm{ml}$ was capable of inhibiting $50 \%$ of the free radicals $\left(\mathrm{IC}_{50}\right)$. Anabaena extract can be thus considered as excellent antioxidant since its $\mathrm{IC}_{50}$ is a small concentration value and it is agreed that a low $\mathrm{IC}_{50}$ value represents high antioxidant activity (Lefahal et al., 2018).

Polyphenols, because of their significant features such as antibacterial and antioxidant activities, have an important function to play in the oral cavity against certain illnesses, pathogens and oral cancers (Kharouf $\boldsymbol{e t}$ al., 2020). In the present study, the 
phenolic compounds present in Anabaena extract were determined by HPLC analysis and the confirmed compounds are given in Table (2). The phenolic compounds detected in Anabaena extract were salicylic acid, gallic acid, tannic acid, caffeic acid and benzoic acid. The highest concentrations determined in Anabaena extract were for salicylic and tannic acids. Salicylic acid is a phenolic plant hormone that was reported to inhibit the proliferation of oral flora (Kolpan and Bartelink, 2019). Tannic acid is a polyphenol that have been reported for its several applications in dentistry as a desensitizing agent, astringent, and surface treatment for smear layer removal (Bedran-Russo et al., 2009).

Caffeic acid has proven to have anti-inflammatory activity which is very important in the case of dental caries that causes acute reversible pulpitis (Alba et al., 2016). Gallic acid and its esters are hydroxybenzoic derivatives, which are used as antioxidant and its importance in dentistry has been previously confirmed (Christopher et al., 2016). Benzoic acid has emerged as an effective method of denture cleansing and has inhibitory effects against the colonization of bacteria on the surfaces of dentures(Arafa, 2016).

Table (2): Quantitative content of phenolic compounds in Anabeana extract

\begin{tabular}{ll}
\hline Phenolic compound & Concentration (ppm) \\
\hline Salicylic acid & 586518.5 \\
Gallic acid & 282.49 \\
Tannic acid & 12956.52 \\
Caffeic acid & 2201.97 \\
Benzoic acid & 850.05 \\
Butaylated hydroxyl toluene (BHT) & Not detected \\
Quercetin & Not detected \\
Pyrogallol & Not detected \\
\hline
\end{tabular}

\section{Anabaena extract antibacterial activity against $S$. mutans}

The gram-positive bacteria Streptococcus mutans are present in the human mouth, more precisely, in multi-species biofilms on the surface of the teeth. These bacteria are the main cariogenic organisms resulting from their ability to generate vast amounts of glucans as well as acid, increasing the salivary buffering capability, which gives the bacteria an advantage over noncariogenic commensal species in low $\mathrm{pH}$ conditions. (Metwalli et al., 2013). Decreasing the bacterial load of the oral cavity is thus one of the 
basic biological strategies for the prevention of dental caries (Wassel and Khattab, 2017).

In the present work the ability of Anabaena extract to inhibit $S$. mutans was tested and the results are illustrated in Figure 2. It was observed that the extract has an inhibitory effect against $S$. mutans and showed an inhibition zone diameter $13(\mathrm{~mm})$. The antibacterial activity of the extract could be largely attributed to the different phenolic compounds determined by HPLC analysis. It is generally agreed phenolic compounds involve many sites of action at the cellular level and many researchers explained this phenomenon by modifying the permeability of cell membranes, by modifying the various intracellular functions caused by hydrogen binding of phenolic compounds to enzymes or by altering the rigidity of the cell wall with integrity losses due to various interactions with the cell membrane. (Bouarab-Chibane et al., 2019).

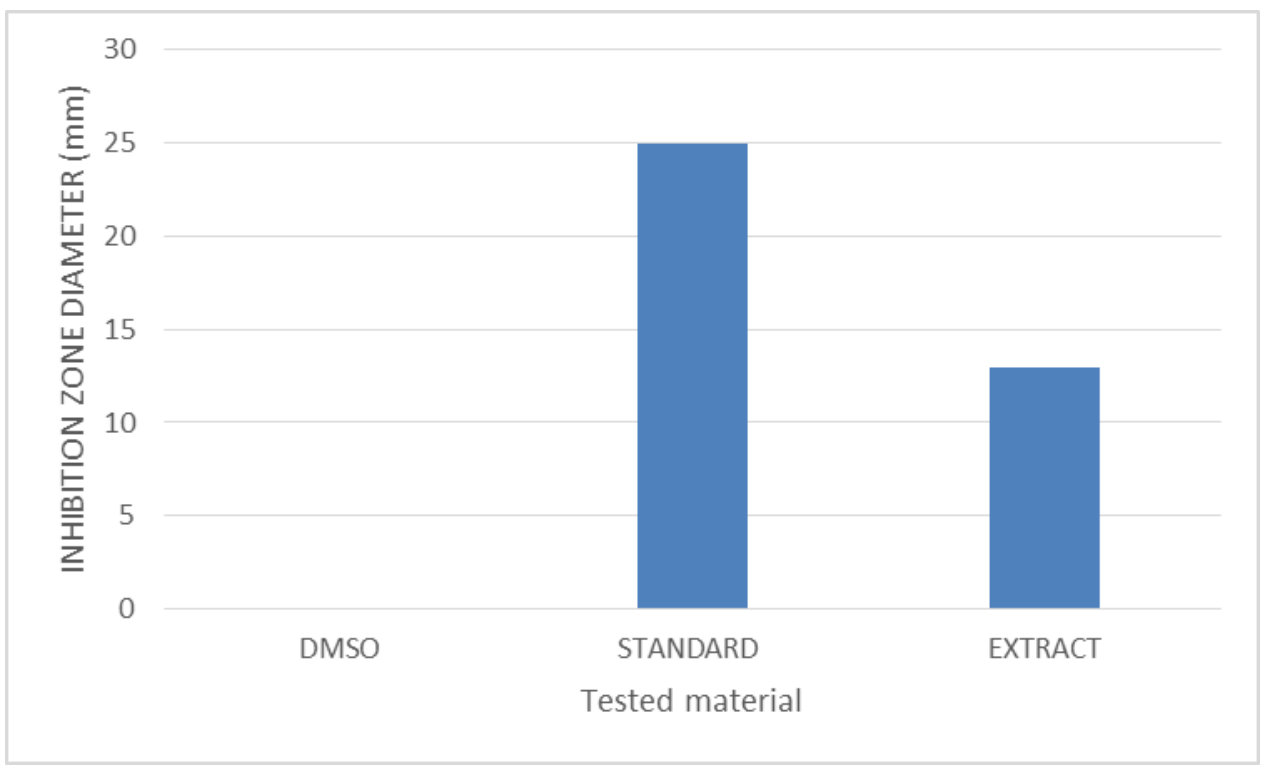

Fig. 2: Antibacterial activity of Anabaena extract against $S$. mutans

\section{CONCLUSION}

In conclusion, Microalgae have been reported to exhibit interesting bioactive properties. Anabaena extract was proved to possess notable antioxidant capacity and also good phenolic compounds content along with its inhibitory effect against $S$. mutans. It can conclude that these Anabeana extract possess the potential antibacterial substances that can be used against oral pathogens. 


\section{REFERENCES}

Abd El-Aty, A.M.; Mohamed, A.A. and Samhan, F.A. (2014). In vitro antioxidant and antibacterial activities of two fresh water Cyanobacterial species, Oscillatoria agardhii and Anabaena sphaerica. J. Appl. Pharm. Sci., 4: 69-75.

Aksakalli, S. (2013). Antioxidants In Dentistry: Review Of Literature. Dentistry, 4: 1-3.

Alba, J.D.M.; Hernández, S.I.M.; López, G.C.V. and Flores, M.A. (2016). Efecto antiinflamatorio del ácido cafeico sobre la pulpitis en un modelo experimental en Cobayos. Rev. ADM, 73: 250-254.

Aliyu A. B.; Ibrahim, M. A.; Musa, A. M. and Musa, A.O. (2013). Free radical scavenging and total antioxidant capacity of root extracts of Anchomanes difformis Engl. (Araceae). Acta Pol Pharm., 70: 115-121.

Arafa, K.O. (2016). Efficacy of benzoic acid denture cleansing against the colonization of Candida albicans. Saudi J. Heal. Sci., 5(2):76-80.

Araújo, I.J. de S.; Carvalho, M.S. de.; Oliveira, T.R. de.; Puppin-Rontani, R.M.; Höfling, J.F.; Mattos-Graner, R. de O. and Stipp, R.N. (2019). Antimicrobial activity of mouth rinses against bacteria that initially colonizes dental's surface. Rev Odontol UNESP, 48: 1-10.

Athmouni, K.; Belghith, T.; Bellassouad, K.; Feki, A. El. Ayadi, H. (2015). Effect of extraction solvents on the biomolecules and antioxidant properties of scorzonera undulata (asteraceae): Application of factorial design optimization phenolic extraction. Acta Sci. Pol. Technol. Aliment., 14: 313-320.

Bedran-Russo, A.K.B.; Yoo, K.J.; Ema, K.C. and Pashley, D.H. (2009). Mechanical properties of tannic-acid-treated dentin matrix. J. Dent. Res., 88: 807-811.

Bogdan, C.; Pop, A.; Iurian, S.M.; Benedec, D. and Moldovan, M.L. (2020). Research advances in the use of bioactive compounds from vitis vinifera byproducts in oral care. Antioxidants, 9: 1-33.

Bouarab-Chibane, L.; Forquet, V.; Lantéri, P.; Clément, Y.; Léonard-Akkari, L.; Oulahal, N.; Degraeve, P. and Bordes, C. (2019). Antibacterial properties of polyphenols: Characterization and QSAR (Quantitative structure-activity relationship) models. Front. Microbiol., 10: 1-23.

Christopher, S.R.; Mathai, V.; Nair, R.S. and Angelo, J.M.C. (2016). The effect of three different antioxidants on the dentinal tubular penetration of Resilon and Real Seal SE on sodium hypochlorite-treated root canal dentin: An in vitro study. J. Conserv. Dent., 19:161-165.

El-Chaghaby, G.A.; Rashad, S.; Abdel-Kader, S.F.; Rawash, E.-S.A.and Moneem, M.A. (2019). Assessment of phytochemical components, proximate composition and antioxidant properties of Scenedesmus obliquus, Chlorella vulgaris and Spirulina platensis algae extracts. Egypt. J. Aquat. Biol. Fish., 23(4): 521 - 526

Jerez-Martel, I.; García-Poza, S.; Rodríguez-Martel, G.; Rico, M.; Afonso-Olivares, C. and Gómez-Pinchetti, J.L. (2017). Phenolic profile and antioxidant activity of crude extracts from microalgae and cyanobacteria strains. J. Food Qual., 2017:1-8.

Kharouf, N.; Haikel, Y. and Ball, V. (2020). Review Polyphenols in Dental Applications. Bioengineering, 7(3): 72-82.

Kolpan, K.E. and Bartelink, E.J. (2019). Dental disease in prehistoric Central California: sex differences in early period Windmiller populations. Archaeol. 
Anthropol. Sci., 11: 3001-3012.

Lefahal, M.; Zaabat, N.; Ayad, R.; Makhloufi, E.; Djarri, L.; Benahmed, M.; Laouer, H.; Nieto, G.and Akkal, S. (2018). Contents , Antioxidant and Photoprotective Activities of Crude Methanolic Extract of Aerial Parts of Growing in Algeria. Med., 5: 1-10.

Metwalli, K.H.; Khan, S.A.; Krom, B.P. and Jabra-Rizk, M.A. (2013). Streptococcus mutans, Candida albicans, and the Human Mouth: A Sticky Situation. PLoS Pathog. 9(10): 1-5.

Mohdaly, A.; Sarhan, M.; Smetanska, I. and Mahmoud, A. (2010). Antioxidant properties of various solvent extracts of potato peel, sugar beet pulp and sesame cake. J Sci Food Agr., 90: 218-226.

Mufeed, A.; Reshma, V.J.; Bharadwaj, P. and Kaushik, P.C. (2014). Role of Antioxidants in Dentistry. J. Dent. Panacea., 1(2): 62- 67.

Prieto, P.1.; Pineda, M. and Aguilar, M. (1999). Spectrophotometric quantitation of antioxidant capacity through the formation of a phosphomolybdenum complex: specific application to the determination of vitamin E. Anal Biochem., 269(2):337-341.

Rashad, S. and El-Chaghaby, G.A. (2020). Marine Algae in Egypt: distribution, phytochemical composition and biological uses as bioactive resources (A review). Egypt. J. Aquat. Biol. Fish., 24(5): $147-160$.

Rashad, S.; El-Chaghaby, G.A. and Elchaghaby, M. A. (2019). Antibacterial activity of silver nanoparticles biosynthesized using Spirulina platensis microalgae extract against oral pathogens. Egypt. J. Aquat. Biol. Fish., 23: 261-266.

Rashad, S.; El-Hassanin, A.S.; Mostafa, S.S.M. and El-Chaghaby, G.A. (2018). Global Journal of Environmental Science and Management Cyanobacteria cultivation using olive milling wastewater for bio-fertilization of celery plant. Glob. J. Environ. Sci. Manag., 5:167-174.

Sarangarajan, R.; Meera, S.; Rukkumani, R.; Sankar, P. and Anuradha, G. (2017). Antioxidants: Friend or foe. Asian Pac. J. Trop. Med., 10: 1111-1116.

Seddek, N.H.; Fawzy, M.A.; El-Said, W.A. and Ahmed, M.M.R. (2019). Evaluation of antimicrobial, antioxidant and cytotoxic activities and characterization of bioactive substances from freshwater blue-green algae. Glob. Nest J., 21: 328-336.

Singh, D.P.; Prabha, R.; Verma, S.; Meena, K.K. and Yandigeri, M. (2017). Antioxidant properties and polyphenolic content in terrestrial cyanobacteria. Biotech., 7: 1-14.

Turkmen, N.; Sari, F. and Velioglu, Y.S. (2006). Effect of extraction solvents on concentration and antioxidant activity of black and black mate polyphenols determined by ferrous tartrate and Folin-Ciocalteu methods. Food Chem., 99: 838-841.

Wassel, M.O. and Khattab, M.A. (2017). Antibacterial activity against Streptococcus mutans and inhibition of bacterial induced enamel demineralization of propolis, miswak, and chitosan nanoparticles based dental varnishes. J. Adv. Res., 8: 387-392.

Yücer, T.D.; Beyatlı, Y. and Pabuçcu, K. (2018). The antiproliferative and antimicrobial effects of cultivated anabaena circinalis rabenhorts ex bornet and flahault and nostoc entophytum bornet and flahault. Trop. J. Pharm. Res., 17:15711577.

Zhou, Y.; Millhouse, E.; Shaw, T.; Lappin, D.F.; Rajendran, R.; Bagg, J.; Lin, H. and Ramage, G. (2018). Evaluating Streptococcus mutans strain dependent characteristics in a polymicrobial biofilm community. Front. Microbiol., 9: 1-10. 